\title{
Preintervention risk stratification of renal pelvic cancer and ureteral cancer should differ
}

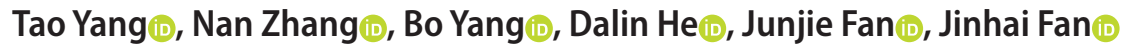 \\ Department of Urology, the First Affiliated Hospital of Xi'an Jiaotong University, Xi'an, China
}

Purpose: To identify different preintervention prognostic factors between renal pelvic cancer (RPc) and ureteral cancer (Uc) and to develop different preintervention risk stratifications for each cancer type.

Materials and Methods: A total of 1,768 patients with organ-confined upper urinary tract urothelial carcinoma (1,067 patients with RPc and 701 with Uc) who presented between 2004 and 2015 were selected from the Surveillance, Epidemiology, and End Results database. Clinicopathologic characteristics were compared between RPc and Uc. Univariable and multivariable Cox regression models were used to examine the prognostic ability of the clinicopathologic characteristics with respect to oncology outcomes.

Results: Age greater than 75 years was significantly associated with cancer-specific survival (CSS) in RPc patients but not in Uc patients. Tumor size had a significant influence on CSS in Uc patients but not in RPc patients; in contrast, age had an influence in RPc but not in Uc. Unlike CSS, age was significantly associated with overall survival (OS) in both RPc and Uc. Tumor size had an effect on OS in Uc patients but not in RPc patients.

Conclusions: The preintervention prognostic factors differed between RPc and Uc. Thus, we should develop separate preintervention risk stratification standards for RPc and Uc. Using these specific preintervention risk stratifications, we may be able to select the most appropriate surgical options for patients in the clinic.

Keywords: Prognosis; Risk factors; Ureteral neoplasms

This is an Open Access article distributed under the terms of the Creative Commons Attribution Non-Commercial License (http://creativecommons.org/licenses/by-nc/4.0) which permits unrestricted non-commercial use, distribution, and reproduction in any medium, provided the original work is properly cited.

\section{INTRODUCTION}

According to the guidelines of the European Association of Urology (EAU), as well as most clinical studies, renal pelvic cancer (RPc) and ureteral cancer (Uc) are considered an integral group and are collectively referred to as upper urinary tract urothelial carcinoma (UTUC). The rationale for this combined grouping is that both the renal pelvis and the ureter are derived from the mesoderm, and their cancers show similar etiology, clinical features, and diagnosis [1]. In the clinical treatment of RPc and Uc, only one preinterven- tion risk stratification standard is used to divide patients into low-risk and high-risk groups, and a surgical procedure is then selected according to the results of the risk stratification: kidney-sparing surgery (KSS) for low-risk patients and radical nephroureterectomy (RNU) for high-risk patients.

However, the renal pelvis and the ureter are two different organs with specific anatomic structures and surrounding tissues. These variations result in differences between $\mathrm{RPc}$ and Uc. For example, patients with Uc are more likely to experience hydronephrosis, which can cause flank pain and become very noticeable to the patient, whereas patients

Received: October 17, 2019 • Accepted: February 4, 2020

Corresponding Author: Jinhai Fan (iD https://orcid.org/0000-0002-0153-1159

Department of Urology, the First Affiliated Hospital of Xi'an Jiaotong University. \#277 Yanta West Road, Xi'an, 710061, Shaanxi Province, China

TEL: +86-29-85323661, FAX: +86-29-85323661, E-mail: jinhaif029@126.com 
with RPc do not experience this symptom. In addition, Uc can directly invade the surrounding tissues, whereas RPc must invade the renal parenchyma before it invades the surrounding Gerota fascia [2] In addition to the abovementioned differences, the tumor characteristics of each cancer also differ; for instance, $55 \%$ to $75 \%$ of Uc cases are low-grade and low-stage, approximately $85 \%$ of RPc cases are papillary, and squamous cell cancers are six times as frequent in the renal pelvis as in the ureter [3,4]. Moreover, an increasing number of recent studies have reported different oncologic outcomes of RPc and Uc, even if the stage or grade of the cancers was similar [2,5-7].

Considering these differences, some authors disagree that the same preintervention risk stratification standard be used for both RPc and Uc [2,5,8]. Therefore, whether we can still use this risk stratification standard for both RPc and Uc remains controversial.

In the present study, owing to the small number of patients with UTUC, we aimed to use the Surveillance, Epidemiology, and End Results (SEER) database to identify different preintervention prognostic factors for patients with $\mathrm{RPc}$ and Uc, which enabled us to develop a preintervention risk stratification for each of these cancers and to select a more appropriate treatment approach for patients.

\section{MATERIALS AND METHODS}

\section{Data source and patients}

In this study, data were obtained from the SEER database released in 2018. SEER*Stat software (ver. 8.3.5) was used in client-server mode to perform all data queries. We obtained access to the SEER database, along with additional information, for research purposes only.

After identifying patients with RPc or Uc (the primary cancer site located in the renal pelvis or ureter using the code C65.9 or C66.9, respectively), we excluded patients with non-organ-confined (pT3+ or $\mathrm{N}+$ or $\mathrm{M}+$ ) cancer. We focused on patients with organ-confined disease ( $\leq \mathrm{pT} 2$ and N0M0) because KSS can only be considered when the cancer is not invasive and when patients can be distinguished from those with pT3 or higher disease by preoperative clinical examination; in contrast, those with pT1 and pT2 disease cannot be clinically distinguished from each other before surgery. The other exclusion criteria were as follows: 1) patients diagnosed before 2004, 2) patients without primary site surgery, 3) patients with more than one primary tumor, 4) patients who underwent radiotherapy and/or chemotherapy, and 5) patients with incomplete information on tumor stage, grade, size, chemotherapy, radiation, and survival.

\section{Variables}

From the SEER database, we gathered information on the location of the tumor, age, sex, race, year of diagnosis, laterality, tumor stage, grade, size, histologic type, additional therapy information (chemotherapy and radiation), and follow-up information (survival months, cause-specific death, and other cause of death).

Patients were divided into five groups according to age $(\leq 54,55-64,65-74,75-84$, and $\geq 85$ years). According to this group, we sought to determine whether age has a prognostic role, and if so, at what age patients have a worse prognosis. Diagnosis was divided into two groups according to year (2004-2009 and 2010-2015) because we collected data for 12 years and divided the time period in half for balance. Patients were also divided into three groups based on race/ ethnicity (white, black, and other). For tumor grade, we combined grade I (well differentiated) and grade II (moderately differentiated) tumors into one group because most tumors classified as grade II according to the 1973 World Health Organization (WHO) classification were reassigned as lowgrade carcinoma according to the $2004 \mathrm{WHO}$ classification [9]. Histologic type was classified as transitional cell carcinoma or variant histology.

The outcomes were cancer-specific survival (CSS) (failure was patient death due to UTUC) and overall survival (OS) (failure was patient death due to any cause).

\section{Statistical analyses}

Patients were divided into two groups according to the primary tumor location, and the chi-square test and Fisher's exact method were used to evaluate the association between tumor location and clinicopathologic features. We estimated Kaplan-Meier survival functions and performed log-rank tests to assess associations between tumor location and time to survival. Next, univariable and multivariable Cox proportional hazards regression models were used to examine the prognostic role of each clinicopathologic characteristic in patients with RPc and Uc, respectively. All p-values are twosided, and statistical significance was set at less than 0.05 . All analyses were performed with PASW Statistics (ver. 18.0; SPSS Inc,, Chicago, IL, USA).

\section{RESULTS}

We identified 15,080 patients with either RPc or Uc who presented from 2004 to 2015. According to the exclusion criteria mentioned above, a total of 1,768 patients met our inclusion criteria for further analysis. The exclusion details are shown in Supplementary Fig. 1. 
Of the 1,768 patients, 1,067 (60.4\%) were diagnosed with $\mathrm{RPc}$ and 701 (39.6\%) were diagnosed with Uc. Detailed information on the patients' clinical characteristics is listed in Table 1. Compared with the RPc group, the Uc group was more likely to contain older patients. Sex, laterality, and tumor grade were similar between the two groups; however, patients with RPc were more likely to be black and to have more $\mathrm{T} 1$ stage tumors, a larger tumor size, and lower pathologic variation.

A Kaplan-Meier analysis revealed that patients with Uc had lower CSS and OS than did patients with RPc ( $\mathrm{p}=0.003$ and 0.003, respectively) (Fig. 1). To further investigate the impact of the preintervention prognostic factors on survival, we performed a Cox regression analysis of patients with either RPc or Uc. As shown in Table 2, age greater than 75 years had a significant association with CSS in RPc patients but not in Uc patients. Tumor grade had prognostic roles in CSS in both RPc and Uc patients, but notably, only grade IV cancer had a negative influence on CSS in Uc patients. Interestingly, tumor size had a significant influence on CSS in Uc patients but not in RPc patients, just as age had an influence in RPc but not in Uc.

The Cox regression analysis of the association between variables and OS in patients with RPc and Uc is shown in Table 3. Unlike CSS, age demonstrated a significant association with OS not only in RPc but also in Uc, although this association was only observed when the age of Uc patients was greater than 75 years. The association of tumor grade with OS remained in both RPc and Uc patients. Similar to CSS, tumor size had an effect on OS in Uc patients but not

Table 1. Characteristics of 1,768 patients with organ-confined upper urinary tract urothelial carcinoma

\begin{tabular}{|c|c|c|c|c|}
\hline Variable & Total & Renal pelvis & Ureter & p-value \\
\hline No. of patients & 1,768 & 1,067 & 701 & \\
\hline Year of diagnosis & & & & 0.039 \\
\hline 2004-2009 & $805(45.5)$ & $507(47.5)$ & $298(42.5)$ & \\
\hline 2010-2015 & $963(54.5)$ & $560(52.5)$ & $403(57.5)$ & \\
\hline Age (y) & & & & 0.002 \\
\hline$\leq 54$ & $150(8.5)$ & 109 (10.2) & $41(5.8)$ & \\
\hline $55-64$ & 341 (19.3) & $222(20.8)$ & $119(17.0)$ & \\
\hline $65-74$ & $552(31.2)$ & $325(30.5)$ & $227(32.4)$ & \\
\hline $75-84$ & $532(30.1)$ & $299(28.0)$ & $233(33.2)$ & \\
\hline$\geq 85$ & $193(10.9)$ & $112(10.5)$ & 81 (11.6) & \\
\hline Sex & & & & 0.762 \\
\hline Male & $996(56.3)$ & $598(56.0)$ & $398(56.8)$ & \\
\hline Female & $772(43.7)$ & $469(44.0)$ & 303 (43.2) & \\
\hline Race & & & & 0.007 \\
\hline White & $1,537(86.9)$ & $925(86.7)$ & $612(87.3)$ & \\
\hline Black & $80(4.5)$ & $60(5.6)$ & $20(2.9)$ & \\
\hline Other & $151(8.5)$ & $82(7.7)$ & $69(9.8)$ & \\
\hline Laterality & & & & 0.554 \\
\hline Left & $888(50.2)$ & $542(50.8)$ & $346(49.4)$ & \\
\hline Right & $880(49.8)$ & 525 (49.2) & $355(50.6)$ & \\
\hline Stage & & & & $<0.001$ \\
\hline pT1 & $1,152(65.2)$ & 771 (72.3) & $381(54.4)$ & \\
\hline pT2 & $616(34.8)$ & $296(27.7)$ & $320(45.6)$ & \\
\hline Grade & & & & 0.099 \\
\hline I and II & $563(31.8)$ & $344(32.2)$ & 219 (31.2) & \\
\hline III & $397(22.5)$ & 255 (23.9) & $142(20.3)$ & \\
\hline IV & $808(45.7)$ & $468(43.9)$ & $340(48.5)$ & \\
\hline Tumor size $(\mathrm{cm})$ & & & & $<0.001$ \\
\hline$\leq 1$ & $145(8.2)$ & $53(5.0)$ & $92(13.1)$ & \\
\hline$>1$ and $\leq 3$ & $756(42.8)$ & $436(40.9)$ & $320(45.6)$ & \\
\hline$>3$ & $867(49.0)$ & $578(54.2)$ & $289(41.2)$ & \\
\hline Histological type & & & & 0.045 \\
\hline TCC & $1,718(97.2)$ & $1,030(96.5)$ & $688(98.1)$ & \\
\hline Variant & $50(2.8)$ & $37(3.5)$ & $13(1.9)$ & \\
\hline
\end{tabular}

Values are presented as number only or number (\%).

TCC, transitional cell carcinoma. 
A

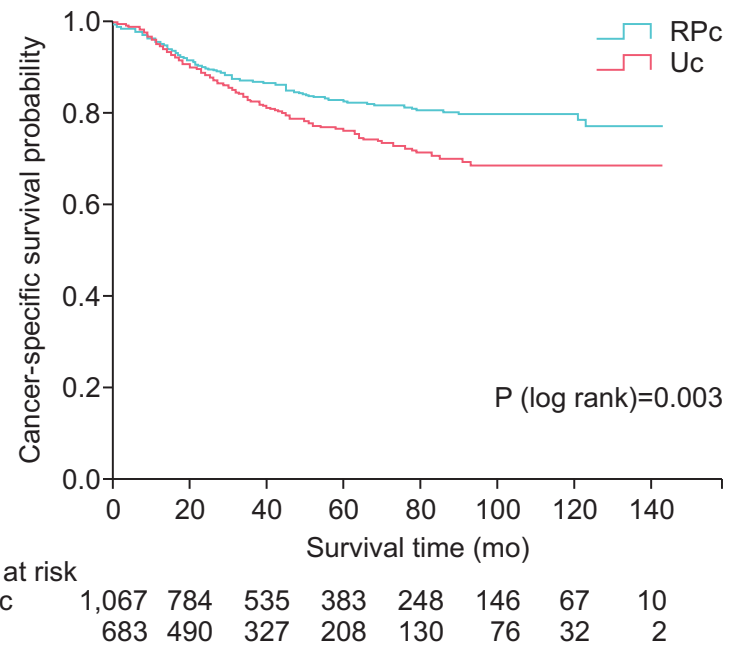

B

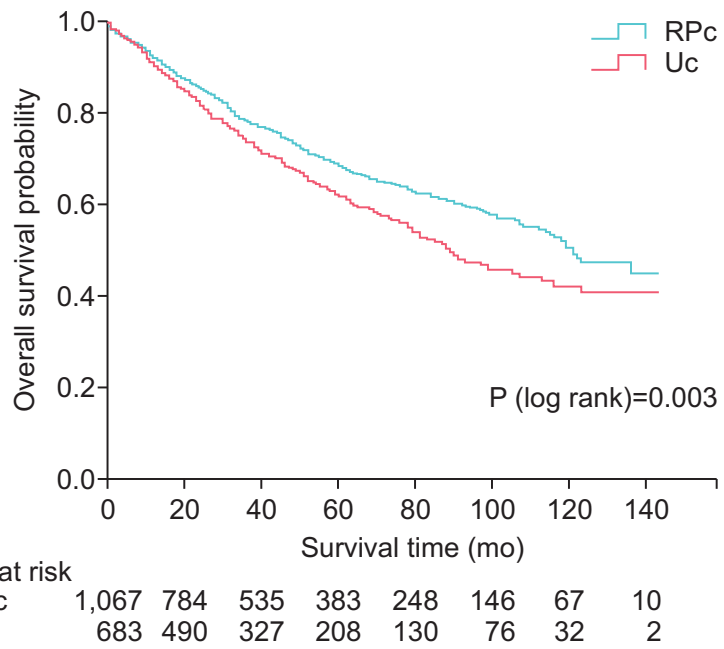

Fig. 1. Kaplan-Meier curves of cancer-specific survival (A) and overall survival (B). RPc, renal pelvic cancer; Uc, ureteral cancer.

in RPc patients.

\section{DISCUSSION}

The information described above supports that RPc and Uc are undoubtably two different tumors. However, for these two cancer types, only one preintervention risk stratification has been used, and surgical options, KSS or RNU, have been confirmed according to the results of the tumor risk stratification. Moreover, although some previous studies have identified the prognostic factors of UTUC, such as tumor stage and grade, among others [10-15], it is notable that all these studies considered RPc and Uc as one integral group, and the differences between them mentioned above were ignored; thus, their conclusions may not be appropriate for patients with one of these two types of cancer. To select more appropriate surgical options, we aimed to determine the different preintervention prognostic factors between RPc and Uc and to develop risk stratification criteria for each type of cancer.

We used the SEER database in this study because of the low number of UTUC cases. Thus, we focused on organconfined disease ( $\leq \mathrm{pT} 2, \mathrm{~N} 0$, and $\mathrm{M} 0)$ for the two reasons described below. First, KSS should be considered only if the tumor is not invasive, but it is difficult to distinguish between pT1 and pT2 tumors according to preoperative examinations, such as preoperative computerized tomography and/ or magnetic resonance imaging. However, pT2 stage or less can be roughly distinguished from pT3 or greater. Therefore, for this study, we selected patients from the SEER database with pT2 or lower-stage tumors. Second, some predictive tools for non-organ-confined disease have been developed in some studies [14,16,17] and reviews [18,19], but to our knowledge, no prediction tool has been established for organ-confined cancer.

Interestingly, after the multivariate analysis, we found that advanced age was significantly associated with both the CSS and OS of RPc patients, whereas in Uc, advanced age was associated with OS only. Large multi-institutional studies have not identified age as a prognostic factor for survival [20,21], even though it has been associated with survival in more aggressive tumors [22]. In the EAU guideline for UTUC, age is no longer considered an independent prognostic factor, and therefore it was not included in the preintervention risk stratification standard of UTUC. However, as mentioned above, most of these studies considered $\mathrm{RPc}$ and Uc as a single group and ignored the differences between them.

Similar to age, the prognostic role of tumor size in survival outcomes remains unclear $[23,24]$ despite the worse influence of larger tumors [25,26]. Tumors larger than $1 \mathrm{~cm}$ are considered high-risk tumors in the EAU guidelines [27], and some studies have shown that tumors $>3$ to $4 \mathrm{~cm}$ may be associated with a worse survival and a higher risk for bladder cancer recurrence $[26,28,29]$. Therefore, we divided patients into three groups ( $\leq 1 \mathrm{~cm}, 1$ to $3 \mathrm{~cm},>3 \mathrm{~cm}$ ) according to tumor size and found that tumor size was associated with Uc only and not RPc, which was the opposite of that observed for age. The reason behind this observation may be that Uc can be detected early because it is more likely to cause hydronephrosis and flank pain. On the basis of this result, we can include tumor size in the preintervention risk stratification standard for Uc but not the standard for RPc.

Our study had several limitations. First, this study was nonrandomized and retrospective in nature, which inevitably leads to data limitations. Moreover, some preoperative 
Table 2. Results of Cox regression analyses evaluating variables associated with cancer-specific survival

\begin{tabular}{|c|c|c|c|c|c|c|c|c|}
\hline \multirow{3}{*}{ Variable } & \multicolumn{4}{|c|}{ Renal pelvic cancer } & \multicolumn{4}{|c|}{ Ureter cancer } \\
\hline & \multicolumn{2}{|c|}{ Univariate analysis } & \multicolumn{2}{|c|}{ Multivariate analysis } & \multicolumn{2}{|c|}{ Univariate analysis } & \multicolumn{2}{|c|}{ Multivariate analysis } \\
\hline & $\mathrm{HR}(95 \% \mathrm{Cl})$ & p-value & $\mathrm{HR}(95 \% \mathrm{Cl})$ & p-value & $\mathrm{HR}(95 \% \mathrm{Cl})$ & p-value & $\mathrm{HR}(95 \% \mathrm{Cl})$ & p-value \\
\hline \multicolumn{9}{|l|}{ Year of diagnosis } \\
\hline 2004-2009 & Reference & & & & Reference & & & \\
\hline 2009-2015 & $\begin{array}{c}0.819 \\
(0.580-1.155)\end{array}$ & 0.255 & & & $\begin{array}{c}0.819 \\
(0.568-1.181)\end{array}$ & 0.284 & & \\
\hline \multicolumn{9}{|l|}{ Age (y) } \\
\hline$\leq 54$ & Reference & & Reference & & Reference & & & \\
\hline $55-64$ & $\begin{array}{c}1.27 \\
(0.580-2.802)\end{array}$ & 0.545 & $\begin{array}{c}1.166 \\
(0.530-2.565)\end{array}$ & 0.703 & $\begin{array}{c}0.577 \\
(0.239-1.394)\end{array}$ & 0.222 & & \\
\hline $65-74$ & $\begin{array}{c}1.514 \\
(0.726-3.158)\end{array}$ & 0.269 & $\begin{array}{c}1.429 \\
(0.684-2.984)\end{array}$ & 0.342 & $\begin{array}{c}1.143 \\
(0.537-2.432)\end{array}$ & 0.730 & & \\
\hline $75-84$ & $\begin{array}{c}2.956 \\
(1.459-5.990)\end{array}$ & 0.003 & $\begin{array}{c}2.537 \\
(1.249-5.152)\end{array}$ & 0.010 & $\begin{array}{c}1.221 \\
(0.574-2.595)\end{array}$ & 0.604 & & \\
\hline$\geq 85$ & $\begin{array}{c}6.103 \\
(2.926-12.731)\end{array}$ & $<0.001$ & $\begin{array}{c}5.385 \\
(2.577-11.25)\end{array}$ & $<0.001$ & $\begin{array}{c}2.140 \\
(0.963-4.754)\end{array}$ & 0.062 & & \\
\hline \multicolumn{9}{|l|}{ Sex } \\
\hline Male & Reference & & & & Reference & & & \\
\hline Female & $\begin{array}{c}0.975 \\
(0.708-1.342)\end{array}$ & 0.875 & & & $\begin{array}{c}1.200 \\
(0.854-1.686)\end{array}$ & 0.294 & & \\
\hline \multicolumn{9}{|l|}{ Race } \\
\hline White & Reference & & & & Reference & & & \\
\hline Black & $\begin{array}{c}1.981 \\
(0.481-2.005)\end{array}$ & 0.959 & & & $\begin{array}{c}1.250 \\
(0.510-3.063)\end{array}$ & 0.625 & & \\
\hline Other & $\begin{array}{c}1.483 \\
(0.882-2.494)\end{array}$ & 0.137 & & & $\begin{array}{c}1.500 \\
(0.911-2.470)\end{array}$ & 0.111 & & \\
\hline \multicolumn{9}{|l|}{ Laterality } \\
\hline Left & Reference & & & & Reference & & & \\
\hline Right & $\begin{array}{c}1.166 \\
(0.849-1.602)\end{array}$ & 0.342 & & & $\begin{array}{c}1.188 \\
(0.844-1.671)\end{array}$ & 0.323 & & \\
\hline \multicolumn{9}{|l|}{ Grade } \\
\hline I and || & Reference & & Reference & & Reference & & Reference & \\
\hline III & $\begin{array}{c}2.489 \\
(1.562-3.968)\end{array}$ & $<0.001$ & $\begin{array}{c}2.219 \\
(1.388-3.546)\end{array}$ & 0.001 & $\begin{array}{c}1.582 \\
(0.928-2.697)\end{array}$ & 0.092 & $\begin{array}{c}1.600 \\
(0.938-2.729)\end{array}$ & 0.085 \\
\hline IV & $\begin{array}{c}2.650 \\
(1.717-4.090)\end{array}$ & $<0.001$ & $\begin{array}{c}2.376 \\
(1.535-3.676)\end{array}$ & $<0.001$ & $\begin{array}{c}2.395 \\
(1.545-3.711)\end{array}$ & 0.000 & $\begin{array}{c}2.468 \\
(1.592-3.827)\end{array}$ & $<0.001$ \\
\hline \multicolumn{9}{|l|}{ Tumor size $(\mathrm{cm})$} \\
\hline$\leq 1$ & Reference & & & & Reference & & Reference & \\
\hline$>1$ and $\leq 3$ & $\begin{array}{c}1.207 \\
(0.483-3.015)\end{array}$ & 0.687 & & & $\begin{array}{c}2.347 \\
(1.122-4.908)\end{array}$ & 0.023 & $\begin{array}{c}2.525 \\
(1.207-5.284)\end{array}$ & 0.014 \\
\hline$>3$ & $\begin{array}{c}1.586 \\
(0.645-3.899)\end{array}$ & 0.315 & & & $\begin{array}{c}2.745 \\
(1.317-5.722)\end{array}$ & 0.007 & $\begin{array}{c}2.899 \\
(1.390-6.044)\end{array}$ & 0.005 \\
\hline \multicolumn{9}{|l|}{ Histological type } \\
\hline TCC & Reference & & & & Reference & & & \\
\hline Variant & $\begin{array}{c}0.811 \\
(0.333-1.979)\end{array}$ & 0.646 & & & $\begin{array}{c}2.228 \\
(0.911-5.449)\end{array}$ & 0.079 & & \\
\hline
\end{tabular}

$\mathrm{HR}$, hazard ratio; $\mathrm{Cl}$, confidence interval; TCC, transitional cell carcinoma.

factors that have been shown to have a prognostic effect, such as body mass index (BMI), ECOG-PS (Eastern Cooperative Oncology Group Performance Status), obesity (BMI>30 $\mathrm{kg} / \mathrm{m}^{2}$ ), and sessile architecture, among others, are not available in the database. Second, we did not consider recurrencefree survival or intravesical recurrence, which is necessary for cancer outcome. Therefore, more clinical research is needed to confirm our results. Third, surgery details are unavailable from the SEER database, which may affect the results because of significant variations between different institutions. 
Table 3. Results of Cox regression analyses evaluating variables associated with overall survival

\begin{tabular}{|c|c|c|c|c|c|c|c|c|}
\hline \multirow{3}{*}{ Variable } & \multicolumn{4}{|c|}{ Renal pelvic cancer } & \multicolumn{4}{|c|}{ Ureter cancer } \\
\hline & \multicolumn{2}{|c|}{ Univariate analysis } & \multicolumn{2}{|c|}{ Multivariate analysis } & \multicolumn{2}{|c|}{ Univariate analysis } & \multicolumn{2}{|c|}{ Multivariate analysis } \\
\hline & $\mathrm{HR}(95 \% \mathrm{Cl})$ & p-value & $\mathrm{HR}(95 \% \mathrm{Cl})$ & p-value & $\mathrm{HR}(95 \% \mathrm{Cl})$ & $p$-value & $\mathrm{HR}(95 \% \mathrm{Cl})$ & p-value \\
\hline \multicolumn{9}{|l|}{ Year of diagnosis } \\
\hline 2004-2009 & Reference & & & & Reference & & & \\
\hline 2009-2015 & $\begin{array}{c}0.837 \\
(0.649-1.080)\end{array}$ & 0.172 & & & $\begin{array}{c}0.773 \\
(0.583-1.024)\end{array}$ & 0.073 & & \\
\hline \multicolumn{9}{|l|}{ Age (y) } \\
\hline$\leq 54$ & Reference & & Reference & & Reference & & Reference & \\
\hline $55-64$ & $\begin{array}{c}1.785 \\
(0.971-3.283)\end{array}$ & 0.062 & $\begin{array}{c}1.672 \\
(0.909-3.078)\end{array}$ & 0.099 & $\begin{array}{c}0.893 \\
(0.391-2.040)\end{array}$ & 0.778 & $\begin{array}{c}0.817 \\
(0.357-1.870)\end{array}$ & 0.632 \\
\hline $65-74$ & $\begin{array}{c}2.406 \\
(1.360-4.254)\end{array}$ & 0.003 & $\begin{array}{c}2.301 \\
(1.300-4.072)\end{array}$ & 0.004 & $\begin{array}{c}2.062 \\
(0.993-4.282)\end{array}$ & 0.052 & $\begin{array}{c}1.898 \\
(0.913-3.945)\end{array}$ & 0.086 \\
\hline $75-84$ & $\begin{array}{c}4.571 \\
(2.622-7.968)\end{array}$ & $<0.001$ & $\begin{array}{c}4.103 \\
(2.348-7.169)\end{array}$ & $<0.001$ & $\begin{array}{c}2.881 \\
(1.400-5.928)\end{array}$ & 0.004 & $\begin{array}{c}2.596 \\
(1.259-5.351)\end{array}$ & 0.010 \\
\hline$\geq 85$ & $\begin{array}{c}10.218 \\
(5.763-18.12)\end{array}$ & $<0.001$ & $\begin{array}{c}9.413 \\
(5.301-16.716)\end{array}$ & $<0.001$ & $\begin{array}{c}4.752 \\
(2.248-10.05)\end{array}$ & $<0.001$ & $\begin{array}{c}4.316 \\
(2.036-9.147)\end{array}$ & $<0.001$ \\
\hline \multicolumn{9}{|l|}{ Sex } \\
\hline Male & Reference & & & & Reference & & & \\
\hline Female & $\begin{array}{c}0.889 \\
(0.713-1.108)\end{array}$ & 0.296 & & & $\begin{array}{c}1.099 \\
(0.856-1.411)\end{array}$ & 0.457 & & \\
\hline \multicolumn{9}{|l|}{ Race } \\
\hline White & Reference & & & & Reference & & & \\
\hline Black & $\begin{array}{c}1.277 \\
(0.827-1.971)\end{array}$ & 0.270 & & & $\begin{array}{c}1.183 \\
(0.607-2.306)\end{array}$ & 0.621 & & \\
\hline Other & $\begin{array}{c}1.098 \\
(0.729-1.653)\end{array}$ & 0.656 & & & $\begin{array}{c}1.239 \\
(0.835-1.838)\end{array}$ & 0.287 & & \\
\hline \multicolumn{9}{|l|}{ Laterality } \\
\hline Left & Reference & & & & Reference & & & \\
\hline Right & $\begin{array}{c}0.992 \\
(0.798-1.234)\end{array}$ & 0.945 & & & $\begin{array}{c}1.261 \\
(0.981-1.621)\end{array}$ & 0.070 & & \\
\hline \multicolumn{9}{|l|}{ Grade } \\
\hline I and II & Reference & & & & Reference & & Reference & \\
\hline III & $\begin{array}{c}1.777 \\
(1.326-2.381)\end{array}$ & $<0.001$ & $\begin{array}{c}1.528 \\
(1.137-2.054)\end{array}$ & 0.005 & $\begin{array}{c}1.573 \\
(1.095-2.261)\end{array}$ & 0.014 & $\begin{array}{c}1.300 \\
(0.901-1.875)\end{array}$ & 0.161 \\
\hline IV & $\begin{array}{c}1.854 \\
(1.410-2.437)\end{array}$ & $<0.001$ & $\begin{array}{c}1.618 \\
(1.229-2.130)\end{array}$ & 0.001 & $\begin{array}{c}1.890 \\
(1.386-2.578)\end{array}$ & $<0.001$ & $\begin{array}{c}1.827 \\
(1.338-2.495)\end{array}$ & $<0.001$ \\
\hline \multicolumn{9}{|l|}{ Tumor size $(\mathrm{cm})$} \\
\hline$\leq 1$ & Reference & & & & Reference & & Reference & \\
\hline$>1$ and $\leq 3$ & $\begin{array}{c}1.080 \\
(0.610-1.910)\end{array}$ & 0.792 & & & $\begin{array}{c}1.814 \\
(1.141-2.882)\end{array}$ & 0.012 & $\begin{array}{c}1.843 \\
(1.158-2.934)\end{array}$ & 0.010 \\
\hline$>3$ & $\begin{array}{c}1.185 \\
(0.675-2.080)\end{array}$ & 0.555 & & & $\begin{array}{c}1.658 \\
(1.038-2.649)\end{array}$ & 0.034 & $\begin{array}{c}1.632 \\
(1.020-2.610)\end{array}$ & 0.041 \\
\hline \multicolumn{9}{|l|}{ Histological type } \\
\hline $\mathrm{TCC}$ & Reference & & & & Reference & & & \\
\hline Variant & $\begin{array}{c}0.488 \\
(0.231-1.033)\end{array}$ & 0.061 & & & $\begin{array}{c}1.623 \\
(0.765-3.442)\end{array}$ & 0.207 & & \\
\hline
\end{tabular}

$\mathrm{HR}$, hazard ratio; $\mathrm{Cl}$, confidence interval; TCC, transitional cell carcinoma.

\section{CONCLUSIONS}

The preintervention prognostic factors differed between RPc and Uc, which should serve as the basis for developing separate preintervention risk stratification standards for $\mathrm{RPc}$ and Uc (advanced age should be included in the risk stratification standard for RPc, and tumor size should be in- cluded in the risk stratification for Uc). With these specific preintervention risk stratifications, we may be able to choose the most appropriate surgical intervention for patients in a clinical setting. 


\section{CONFLICTS OF INTEREST}

The authors have nothing to disclose.

\section{ACKNOWLEDGMENTS}

This study was supported by National Natural Science Foundation of China (no. 81572520).

\section{AUTHORS' CONTRIBUTIONS}

Research conception and design: Jinhai Fan and Dalin He. Data acquisition: Tao Yang, Nan Zhang, and Bo Yang. Statistical analysis: Tao Yang and Junjie Fan. Data analysis and interpretation: Tao Yang and Jinhai Fan. Drafting of the manuscript: Tao Yang. Critical revision of the manuscript: Dalin He. Obtaining funding: Jinhai Fan. Administrative, technical, or material support: Dalin He. Supervision: Jinhai Fan and Dalin He. Approval of the final manuscript: Jinhai Fan.

\section{SUPPLEMENTARY MATERIAL}

Scan this QR code to see the supplementary material, or visit https://www.icurology.org/src/sm/icurology-61-397-s001.pdf.

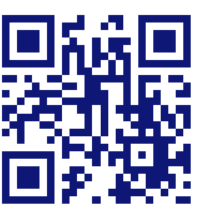

\section{REFERENCES}

1. Rouprêt M, Babjuk M, Compérat E, Zigeuner R, Sylvester RJ, Burger M, et al. European Association of Urology guidelines on upper urinary tract urothelial carcinoma: 2017 update. Eur Urol 2018;73:111-22.

2. Ito K, Kuroda K, Asakuma J, Hamada S, Tachi K, Tasaki S, et al. Preoperative risk factors for extraurothelial recurrence in patients with ureteral cancer treated with radical nephroureterectomy. J Urol 2014;191:1685-92.

3. Cummings KB. Nephroureterectomy: rationale in the management of transitional cell carcinoma of the upper urinary tract. Urol Clin North Am 1980;7:569-78.

4. Stewart JH, Hobbs JB, McCredie MR. Morphologic evidence that analgesic-induced kidney pathology contributes to the progression of tumors of the renal pelvis. Cancer 1999;86:157682.

5. Ito K, Asakuma J, Kuroda K, Tachi K, Sato A, Horiguchi A, et al. Preoperative risk factors for extraurothelial recurrence in N0M0 patients with renal pelvic cancer treated by radical nephroureterectomy. Mol Clin Oncol 2016;4:530-6.

6. Pak RW, Moskowitz EJ, Bagley DH. What is the cost of maintaining a kidney in upper-tract transitional-cell carcinoma? An objective analysis of cost and survival. J Endourol 2009;23:3416.

7. Ouzzane A, Colin P, Xylinas E, Pignot G, Ariane MM, Saint F, et al. Ureteral and multifocal tumours have worse prognosis than renal pelvic tumours in urothelial carcinoma of the upper urinary tract treated by nephroureterectomy. Eur Urol 2011;60:1258-65.

8. Fujimoto H, Nakanishi H, Miki T, Kanayama HO, Ohyama C, Suzuki K, et al. Oncological outcomes of renal pelvic and ureteral cancer patients registered in 2005: the first large population report from the Cancer Registration Committee of the Japanese Urological Association. Int J Urol 2014;21:527-34.

9. MacLennan GT, Kirkali Z, Cheng L. Histologic grading of noninvasive papillary urothelial neoplasms. Eur Urol 2007;51:88997; discussion 897-8.

10. Favaretto RL, Shariat SF, Chade DC, Godoy G, Adamy A, Kaag $\mathrm{M}$, et al. The effect of tumor location on prognosis in patients treated with radical nephroureterectomy at Memorial SloanKettering Cancer Center. Eur Urol 2010;58:574-80.

11. Raman JD, Ng CK, Scherr DS, Margulis V, Lotan Y, Bensalah K, et al. Impact of tumor location on prognosis for patients with upper tract urothelial carcinoma managed by radical nephroureterectomy. Eur Urol 2010;57:1072-9.

12. Cha EK, Shariat SF, Kormaksson M, Novara G, Chromecki TF, Scherr DS, et al. Predicting clinical outcomes after radical nephroureterectomy for upper tract urothelial carcinoma. Eur Urol 2012;61:818-25.

13. Yafi FA, Novara G, Shariat SF, Gupta A, Matsumoto K, Walton TJ, et al. Impact of tumour location versus multifocality in patients with upper tract urothelial carcinoma treated with nephroureterectomy and bladder cuff excision: a homogeneous series without perioperative chemotherapy. BJU Int 2012;110(2 Pt 2):E7-13.

14. Margulis V, Youssef RF, Karakiewicz PI, Lotan Y, Wood CG, Zigeuner R, et al. Preoperative multivariable prognostic model for prediction of nonorgan confined urothelial carcinoma of the upper urinary tract. J Urol 2010;184:453-8.

15. Isbarn H, Jeldres C, Shariat SF, Liberman D, Sun M, Lughezzani G, et al. Location of the primary tumor is not an independent predictor of cancer specific mortality in patients with upper urinary tract urothelial carcinoma. J Urol 2009;182:217781.

16. Brien JC, Shariat SF, Herman MP, Ng CK, Scherr DS, Scoll B, et al. Preoperative hydronephrosis, ureteroscopic biopsy grade 
and urinary cytology can improve prediction of advanced upper tract urothelial carcinoma. J Urol 2010;184:69-73.

17. Favaretto RL, Shariat SF, Savage C, Godoy G, Chade DC, Kaag $\mathrm{M}$, et al. Combining imaging and ureteroscopy variables in a preoperative multivariable model for prediction of muscleinvasive and non-organ confined disease in patients with upper tract urothelial carcinoma. BJU Int 2012;109:77-82.

18. Mbeutcha A, Rouprêt M, Kamat AM, Karakiewicz PI, Lawrentschuk N, Novara G, et al. Prognostic factors and predictive tools for upper tract urothelial carcinoma: a systematic review. World J Urol 2017;35:337-53.

19. Lughezzani G, Burger M, Margulis V, Matin SF, Novara G, Roupret $M$, et al. Prognostic factors in upper urinary tract urothelial carcinomas: a comprehensive review of the current literature. Eur Urol 2012;62:100-14.

20. Shariat SF, Godoy G, Lotan Y, Droller M, Karakiewicz PI, Raman JD, et al. Advanced patient age is associated with inferior cancer-specific survival after radical nephroureterectomy. BJU Int 2010;105:1672-7.

21. Chromecki TF, Ehdaie B, Novara G, Pummer K, Zigeuner R, Seitz C, et al. Chronological age is not an independent predictor of clinical outcomes after radical nephroureterectomy. World J Urol 2011;29:473-80.

22. Yap SA, Schupp CW, Chamie K, Evans CP, Koppie TM. Effect of age on transitional cell carcinoma of the upper urinary tract: presentation, treatment, and outcomes. Urology 2011;78:87-92.

23. Zigeuner R, Shariat SF, Margulis V, Karakiewicz PI, Roscigno
M, Weizer A, et al. Tumour necrosis is an indicator of aggressive biology in patients with urothelial carcinoma of the upper urinary tract. Eur Urol 2010;57:575-81.

24. Seitz C, Gupta A, Shariat SF, Matsumoto K, Kassouf W, Walton TJ, et al. Association of tumor necrosis with pathological features and clinical outcome in 754 patients undergoing radical nephroureterectomy for upper tract urothelial carcinoma: an international validation study. J Urol 2010;184:1895-900.

25. Yuan H, Chen X, Liu L, Yang L, Pu C, Li J, et al. Risk factors for intravesical recurrence after radical nephroureterectomy for upper tract urothelial carcinoma: a meta-analysis. Urol Oncol 2014;32:989-1002.

26. Kates M, Badalato GM, Gupta M, McKiernan JM. Secondary bladder cancer after upper tract urothelial carcinoma in the US population. BJU Int 2012;110:1325-9.

27. Rouprêt M, Babjuk M, Compérat E, Zigeuner R, Sylvester RJ, Burger M, et al. European Association of Urology guidelines on upper urinary tract urothelial cell carcinoma: 2015 update. Eur Urol 2015;68:868-79.

28. Simone G, Papalia R, Loreto A, Leonardo C, Sentinelli S, Gallucci M. Independent prognostic value of tumour diameter and tumour necrosis in upper urinary tract urothelial carcinoma. BJU Int 2009;103:1052-7.

29. Pieras E, Frontera G, Ruiz X, Vicens A, Ozonas M, Pizá P. Concomitant carcinoma in situ and tumour size are prognostic factors for bladder recurrence after nephroureterectomy for upper tract transitional cell carcinoma. BJU Int 2010;106:1319-23. 